\title{
OVERVIEW OF THE SHUTTLE IMAGING RADAR (SIR-C)
}

\author{
D Evans \& C Elachi \\ Jet Propulsion Laboratory \\ California Institute of Technology \\ Pasadena, CA 91109
}

\section{ABSTRACT}

The Shuttle Imaging Radar-C (SIR-C) Experiment is the next evolutionary step in the Spaceborne Imaging Radar Program at the Jet Propulsion Laboratory (JPL). SIR-C is currently scheduled to fly in August, 1991 and again in December, 1992. SIR-C will provide increased capability over Seasat and the two previous Shuttle Imaging Radars by acquiring digital images simultaneously at two microwave frequencies ( $L$ - and $\mathrm{C}$-band) with multiple signal polarizations $(\mathrm{HH}, \mathrm{VV}, \mathrm{HV}$, VH). SIR-C will be a dual bandwidth system so that investigators can choose a high or low resolution mode (20 and $10 \mathrm{MHz}$, respectively). In addition, a German/Italian X-band SAR with VV polarization will be flown with SIR-C, resulting in a three-frequency capability. SIR-C prototype data will be acquired using an Airborne Imaging Radar (AIR) to test several new designs that will be implemented on SIR-C, to develop the overall calibration strategy for SIR-C, and to develop data analysis tools for SIR-C data.

\section{BACKGROUND}

NASA is engaged in a long-term research program in Earth Sciences using remote sensing data acquired with Spaceborne Imaging Radar sensors alone and in conjunction with data from other imaging sensors. The scientific objectives of the SIR Program are: (1) to conduct geoscience investigations that require the observational capabilities of orbiting radar sensors alone, or in conjunction with other sensors, that will lead to a better understanding of the surface conditions and processes on the earth, (2) to explore regions of the earth's surface that are not well characterized because of vegetation, cloud or alluvial cover in order to better understand surface conditions and processes on a global scale. (3) to incorporate this new knowledge into global models of surface and subsurface processes operating on the earth and other planets. The SIR program, which began in 1978 with the launch of the Seasat synthetic aperture radar (SAR), continued in 1981 with the Shuttle Imaging Radar-A (SIR-A) mission and in 1984 with the Shuttle Imaging Radar-B (SIR-B). Seasat and SIR-A acquired L-band radar images at fixed incidence angles of 20 and 47 degrees respectively, while SIR-B provided radar images for a range of incidence angles from 15-60 degrees.

Seasat was launched primarily for oceanographic studies, however the SAR images have been used for both oceanic and land studies, and atlases of Seasat SAR images have been published (Refs. 1 and 2). Seasat SAR images have confirmed that microwave imaging radars are very sensitive to the geometric patterns, forms, and shapes of the earth's surface, as well as to changes in dielectric properties of earth materials, particularly soil moisture properties and ice-water boundaries.

SIR-A provided key results including the imaging of buried drainage channels in a hyperarid region of southern Egypt (e.g. Ref. 3), the imaging of cloudcovered tropical regions, and the repetitive observation of dynamic ocean phenomena. SIR-A coverage consisted of long swaths about $50 \mathrm{~km}$ wide. Approximately $10^{7} \mathrm{~km}^{2}$ of the earth's surface was imaged with $40-\mathrm{m}$ resolution for selected passes between latitudes of $41^{\circ} \mathrm{N}$ and $36^{\circ} \mathrm{S}$.

One of the key scientific objectives of the SIR-B experiment was to demonstrate the capability of stereo imaging. This was successfully achieved over a number of sites. Stereo images were used to generate a digital topographic data base of Mount Shasta. Further, computer processing allowed the generation of perspective views of the mountain from multiple look directions. This demonstrates the enormous potential of using spaceborne stereo radar data for three dimensional analyses of the surface morphology of the earth.

The SIR-B data system provided for onboard digitization of the radar echoes and for data transmission to the ground at $46 \mathrm{Mb} / \mathrm{s}$ through the TDRSS; the data system also provided a digital recording backup through a 30 $\mathrm{Mb} / \mathrm{s}$ onboard tape recorder. Due to a failure of the Shuttle-Tracking and Data Relay Satellite System (TDRSS) communications antenna system, almost all of the SIR-B data were recorded on the tape recorder, thereby leading to a greatly reduced swath. Swath widths of SIR-B data range typically from 10 to $50 \mathrm{~km}$, depending on incidence angle.

The SIR-C Science objectives are summarized in the SIR-C Science Plan (Ref. 4). SIR-C experiments will address geoscientific investigations of the earth's surface and its environment that will lead to an improved understanding of the solid-earth, biospheric, hydrospheric, cryospheric and atmospheric components of the earth system, capitalizing on the observational capabilities of orbiting multiple parameter radar sensors alone or in conjunction with other sensors. Specific objectives will be based on proposed investigations by the SIR-C Science Team. 


\section{THE SIR-C SENSOR}

SIR-C is designed to be versatile enough to meet a varicty of observational requirements. Operational modes will include: dual frequency, single polarization; single frequency, dual polarization; dual frequency. dual polarization; single frequency, quad polarization; and dual frequency, quad polarization. SIR-C will not only provide images of the magnitudes of $\mathrm{HH}, \mathrm{VV}$ and cross-polarized returns, it will also provide images of the relative phase difference between $H H, V V, V H$ and HV returns and will allow derivation of the complete scattering matrix of the scene on a pixel by pixel basis. From the scattering matrix every polarization configuration (linear, circular or elliptical) can be generated by ground processing. The L-band center frequency will be $1.25 \mathrm{GHz}$ and $\mathrm{C}$-band center frequency will be $5.3 \mathrm{GHz}$. The X-SAR center frequency will be $9.6 \mathrm{GHz}$ operating in VV polarization only.

Because the SIR-C Science Working Group recommended a cross-polarized capability at large angles of incidence, a distributed radar approach will be implemented for SIR-C. A distributed SAR has an advantage over a conventional SAR because numerous low-power (solid-state) transmitters, distributed across the antenna aperture, are used instead of a single highpower transmitter. Since large power losses typically occur in the corporate fecd of a conventional antenna, as much as an cight-fold improvement in efficiency can be obtained using a distributed SAR. In addition, solid-state distributed system has a high inherent redundancy and potentially extended lifetime compared to a conventional single-source approach. Another advantage of a distributed antenna is that clectronic scanning in both range and azimuth is more casily implemented than with a conventional antenna. The power, redundancy, and scanning requirements for SIR-C are similar to those for the proposed Eos SAR.

The SIR-C sensor will be composed of several subsystems: the antenna array, the exciter, the receivers, the data-handling network, and the ground SAR processor. The antenna is composed of two planar arrays, one for L-band operation and the other for $C$ band operation. Each array is composed of a uniform grid of dual-polarized microstrip antenna radiators, each polarization port of which is fed by a separate corporate feed network. The overall size of the antenna is $12.0 \times 4.1 \mathrm{~m}$, with the $\mathrm{L}$-band aperture being $12.0 \times 2.8$ $\mathrm{m}$ and the C-band aperture $12.0 \times .8 \mathrm{~m}$

Amplification of the radar pulses (both transmitted and received) will be accomplished in distributed fashion, with solid-state high-power amplifiers (HPA), lownoise amplifiers (LNA), and 4-bit phase shifters distributed across the array. A transmit/receive (T/R) unit is assigned to 18 microstrip elements distributed along the long dimension of the antenna. This will allow the antenna beam to be electronically stecred, thereby eliminating the need for mechanical stecring and providing much more flexibility during the mission for imaging at various incidence angles.

To achieve even more flexibility, SIR-C will provide a choice of partial aperture or full aperture. This choice involves either exciting a portion of the antenna's short dimension or exciting the entire aperture. The use of a portion of the aperture increases the antenna beamwidth and increases the swath width at near-nadir incidence angles.

The transmitter peak power is $3.5 \mathrm{~kW}$ at L-band and 2.2 kW at C-band. As previously pointed out, this peak will be achieved by combining in a coherent fashion the output from 18-element subarrays of microstrip output from 18-element subarrays of microstrip elements on the antenna surface. Each solid-state amplifier is driven through a corporate fecd network by a central radar exciter, one exciter for each frequency. The exciter output is a train of chirped pulses with a $33-\mu \mathrm{s}$ pulse width and a pulse repctition frequency (PRF) that varies from approximately 1200 to $1800 \mathrm{~Hz}$ depending on the Shuttlc altitude and systcm configuration. The bandwidths of the chirp modulator are 10 and $20 \mathrm{MHz}$, at both L.-band and C-band. The Cband exciter signal carrier will be derived from the $L$ band signal by frequency synthesis techniques.

Four solid-statc receivers (back ends) are planned, two for $\mathrm{L}$-band and two for $\mathrm{C}$-band. The radar echoes from cach receiver are routed through a receiver switching network to four digital data handling system (DDHS) networks. These will then be direcled to onboard 100$\mathrm{Mb} / \mathrm{s}$ tape recorders or through the Shuttle-TDRSS Kuband $50-\mathrm{Mb} / \mathrm{s}$ data link. This combination of real-time (TDRSS) or delaycd-time (tape-recorder) data steering allows coverage of virtually any location on the carth over which the Shutlle flies.

Data tapes either brought back with the Shuttle or recorded through TDRSS will be processed at JPL using the Advanced Digital SAR Processor (ADSP), leading to processed SAR images in both computcr-compatible tape (CCT) and film formats. Digital correlation to full resolution will result in images with azimuth resolution of approximately $30 \mathrm{~m}$ at four looks. However, the processor will be versatile cnough to accommodate a user-specificd number of looks. Range resolution will vary from $60 \mathrm{~m}$ at a 15 degrec incidence angle $(\theta)$ to 20 $m$ at an angle of 55 degrees with low resolution (bandwidth $=10 \mathrm{MH} z$ ), and $30 \mathrm{~m}$ at $\theta=15$ to $10 \mathrm{~m}$ at $\theta=55$ with high resolution (bandwidth $=20 \mathrm{MHz}$ ), The SIR-C swath width will depend on the mode, look angle, resolution (bandwidth), signal quantization level, and the surface bcing imaged. Generally, swath width for calibrated data will range from $15-65 \mathrm{~km}$, and swath widths for mapping mode will range from $40-90 \mathrm{~km}$.

Investigations can choose between data acquired at 8 bits per sample or 4 bits per sample. In addition, a Block Floating Point Quantizer (BFPQ) which uses an 8 bit uniform quantizer and transmits 4 bits will be implemented on SIR-C. The 8 bit dynamic range of the SIR-C images is expected to be aboul $40 \mathrm{~dB}$ with $10 \mathrm{~dB}$ SNR. A 4 bit quantization level would reduce the dynamic range to approximately $17 \mathrm{~dB}$. At $10 \mathrm{~dB}$ SNR, $(8,4)$ BFPQ data will have the same dynamic range as 8 bit data. but a swath width corresponding to 4 bit data.

The standard digitally processed $\mathrm{C}$ - and L-band images will be radiometrically calibrated to compensate for drift or changes in transmitter power, receiver gain, antenna pointing, etc. As an cxample of expected precision of relative radiometric calibration, the worstcase calibration would be $3 \mathrm{~dB}$ at the swath edges and 2 $\mathrm{dB}$ at the swath center, the best possible relative calibration is expected to be $1 \mathrm{~dB}$. These errors are primarily due to platform instability. These numbers do not include the effects of spcckle noise, which alone would produce a backscatter variance of $3 \mathrm{~dB}$ for a standard 4-look SIR-C image. The absolute location accuracy of an image pixel relative to a fixed cartographic grid is limited by uncertainties in spacecraft ephemeris, timing, platform velocity, sensor hardware performance, terrain, and ionospheric effects. The magnitude of the crrors in the absolute image-pixel location for SIR-C will also depend on the antenna look angle. The location accuracy of SIR-C special products will be $100 \mathrm{~m}$, not including cphemeris and terrain errors. There will be $<0.1 \%$ distortion (i.e., 
scalc factor plus $s k c w$ ) between any two points relative to a map basc after post-flight cphemeris correction.

\section{BASELINE MISSION}

The first SIR-C Might is planned for August, 1991, with a second flight in December, 1992 to enable data acquisition during two different scasons. SIR-C will collect data during a period of $6-8$ days during each flight. The Shutlle's altitude will be approximately 225 $\mathrm{km}$ during the mission. Ths altitude will result in a one-day repcat cyclc or a slightly drifting orbit depending on the investigators' requirements. The orbital inclination will be 57 degrees and the node crossing will be fixcd based on investigator requirements and Shuttle constraints. Nominally, 50 hours of SIR-C data will be recorded on-board on cach of four channcls for cach flight, in addition to 50 hours of X-SAR data. In addition, a limited amount of SIR-C data may be transmitted to the ground for near reallime digital processing during the mission.

\section{SIR-C PROTOTYPE AIRCRAFT FLIGHTS}

An aircraft prolotype of the SIR-C sensor, the NASA/JPL Airborne Imaging Radar (AIR) is currently in its first ycar of opcrations. The SIR-C Block Floating Point Quantizer, and digital chirp designs have already becn tested with the AIR system, and plans for 1989 include test of the SIR-C signal string breadboard. Plans are to acquire data for Scicnce Tcam members in 1989 as well. AIR requests will be coordinated based on investigator requirements during the initial team mecting in October, 1988. A Calibration Plan for SIR-C will also be developed based on experience gained from calibration of the airborne system. Dihedral and trihedral corner reflectors, and Polarimetric Active Radar Calibrators (PARCs) have all been deployed during aircraft ovcrflights in support of this effort, and results are currently being analyzed. Finally, scveral data analysis tools have becn developed (c.g. Ref. 5) utilizing aircraft data that will be applicable to SIR.C data. These include algorithms to, 1) determine the heterogencity of scatterers within subregions of an image, 2) optimize the relurn power from these arcas, and 3) identify probable scattcring mechanisms for each pixcl in a radar imagc.

\section{ACKNOWLEDGEMENT}

The research described in this paper was carricd out at the Jet Propulsion Laboratory, California Institute of Technology, under NASA Contract NAS7-100.

\section{REFERENCES}

1. Ford J P, Blom R G, Bryan $M$ L, Daily $M$ I, Dixon $\mathbf{T} \mathbf{H}$, Elachi E \& Xenos E C, Seasat views North America, the Caribbean, and Western Europe with imaging radar, JPL Publication 80-67, Jct Propulsion Laboratory, Pasadena, California, November 1, 1980.

2. Fu L L \& Holt B, Seasat vicws occans and sea ice with synthelic-apcrturc radar, $J P L$ Publication 80-67, Jet Propulsion Laboratory, Pasadena, California, Fcbruary 15, 1982.

3. McCaulcy J F, Schaber G G, Breed C S, Grolier M J, Haynes C V. Issawi B, Elachi C \& Blom R 1982, Subsurface valleys and geoarchacology of the Eastern Sahara revealcd by Shuttle radar, Science Vol 218, pp. 1004-1020.
4. The Shuttle Imaging Radar-C Science Plan 1986, JPL Publication 86-29, Jct Propulsion Laboratory, Pasadena, California.

5. Evans D L, Farr T G, van Zyl J J, Zebker H A 1988, Radar polarimetry: Analysis tools and applications, in press IEEE Trans. Geoscience and Remote Sensing. 